\title{
QUALIDADE FISIOLÓGICA E SANITÁRIA DE SEMENTES DE Zinnia elegans Jacq. COLHIDAS EM DIFERENTES ÉPOCAS ${ }^{1}$
}

\author{
DANIELE CARDOSO PEDROSO², VANESSA OCOM MENEZES², MARLOVE FÁTIMA BRIÃO MUNIZ, \\ ROGÉRIO BELLÉ4 ${ }^{4}$ ELENA BLUME 3 , DANTON CAMACHO GARCIA ${ }^{4}$
}

\begin{abstract}
RESUMO - O objetivo do trabalho foi o de avaliar a influência de diferentes épocas de colheita na qualidade fisiológica e sanitária de sementes de zínia. As sementes zínia foram originadas de plantas semeadas em outubro de 2004, na área experimental do Departamento de Fitotecnia (UFSM). Os capítulos foram coletados manualmente e de acordo com a sua aparência em sete épocas: 17 de janeiro, 10 de fevereiro, 15 de março (coleta A), 23 de março (coleta B), 12 de abril, 10 de maio (coleta A) e 29 de maio (coleta B) do ano de 2005. Aqueles provenientes de coletas em janeiro, fevereiro e maio (A) apresentavam-se verdolengos, os demais tinham aparência seca. A qualidade fisiológica das sementes foi avaliada pelos testes de germinação, primeira contagem, classificação do vigor de plântulas, comprimento e massa fresca de plântulas, emergência e comprimento de plantas em campo. Foi determinado ainda o grau de umidade das sementes. A qualidade sanitária, pelo teste do papel filtro, foi avaliada aos sete dias. A época de colheita dos capítulos, de acordo com sua aparência, influencia na qualidade fisiológica e sanitária de sementes de Zinnia elegans Jacq. Sementes colhidas de capítulos em estádio seco, com menor grau de umidade, foram as que apresentaram melhor qualidade fisiológica. Além disso, a ocorrência de patógenos variou conforme a época de colheita, sendo que sementes provenientes da colheita de fevereiro apresentaram maior porcentagem de incidência de Fusarium spp.
\end{abstract}

Termos para indexação: zínia, germinação, vigor, fungos, maturação.

\section{PHYSIOLOGICAL AND SANITARY QUALITY OF Zinia elegans Jacq. SEEDS FROM DIFFERENT HARVEST TIME}

\begin{abstract}
The objective of this work was to evaluate the influence of different harvest time on physiological and sanitary quality of Zínia elegans seeds. The seeds zinia was originated from plants sowed in October of 2004, in the experimental area of the Pyrotechnic Department (UFSM). The chapters were collected manually and in according with appearance in seven times: January 17 th, February 10 th, March 15th (collect A), March 23th (collect B), April 12th, May 10th (collect A) and May 29th (collect B) of 2005. Those proceeding from the collect in January, February and May (A), appeared not quite ripe, the others had a dry appearance. The seed physiological quality was evaluated by the germination test, first counting, moistness degree, seedlings vigor classification, seedlings length and fresh mass, emergence and length of plants in field. The sanitary quality, by blotter test, was evaluated at seven days. The time of harvest of the chapters, according with appearance, influences in the seed physiological and sanitary quality of Zinnia elegans Jacq.. Seeds harvested at
\end{abstract}

${ }^{1}$ Submetido em 25/04/2007. Aceito para publicação 05/06/2008.

${ }^{2}$ Bióloga, mestranda do PPG em Agronomia, Depto de Defesa Fitossanitária, Universidade Federal de Santa Maria (UFSM), danibioufsm@yahoo.com. br, vane_menezes@yahoo.com.br;
${ }^{3}$ Enga. Agra, Dra., Profa. Adjunta, Depto. de Defesa Fitossanitária, UFSM, CEP: 97105-900. Santa Maria-RS, marlove@smail.ufsm.br; eblume@, smail.ufsm.br

${ }^{4} \mathrm{Eng}^{\mathrm{o}}$. Agr ${ }^{\mathrm{o}}$, Dr., Prof ${ }^{\mathrm{o}}$. Adjunto, Depto. de Fitotecnia, UFSM, CEP:97105900, Santa Maria-RS, belle@smail.com.br; danton@smail.ufsm.br. 
dry stadium, with smaller humidity degree, were the ones that presented better physiologic quality. Besides, the pathogen occurrence varied according to the harvest season, being seeds from February harvest presented a larger percentage of Fusarium spp incidence

Keywords: Zinia, germination, vigor, fungi, maturacion.

\section{INTRODUÇÃO}

A produção e o consumo de flores e plantas ornamentais no Brasil crescem a cada ano acompanhando a expansão mundial. O Brasil já se projeta no cenário internacional como importante referencial de qualidade e competitividade (Junquera e Peetz, 2002).

Zinnia elegans Jacq. (zínia) é uma angiosperma pertencente à família Asteraceae, que apresenta características favoráveis para o cultivo em vasos visando ornamentação. Dentre elas, destacam-se a possibilidade de ser cultivada em qualquer época do ano (Lorenzi e Souza, 1999), a abundância e a diversidade de cores de suas flores e a grande variedade de forma de suas brácteas (Torres, 1963). Além disso, zínia apresenta um longo período de florescimento, pois após cada colheita, as gemas localizadas na base dos ramos se desenvolvem, resultando na emissão de novos ramos e, conseqüentemente, de novas flores. Porém, o longo período de florescimento representa um obstáculo à obtenção de sementes de elevado vigor e com idade fisiológica uniforme, visto que inflorescências de idades e tamanhos diferentes são colhidas conjuntamente. Por isso, as sementes de zínia geralmente apresentam baixo poder de germinação, principalmente quando se emprega a semeadura direta no campo para o estabelecimento da cultura (Guimarães et al., 1998).

Em função da crescente importância das espécies ornamentais, observa-se a demanda por sementes de boa qualidade e se fazem necessários estudos visando incrementos e melhoria na produção de sementes, bem como maior conhecimento sobre as épocas mais adequadas para a colheita.

A qualidade da semente é o somatório de atributos genéticos, físicos, fisiológicos e sanitários que afetam a sua capacidade de originar plantas de alta produtividade. A qualidade fisiológica da semente significa sua capacidade para desenvolver funções vitais, abrangendo germinação, vigor e longevidade (Popinigis, 1985). Já a qualidade sanitária é conseqüência da ação integrada de uma série de fatores, que ocorrem durante todo o processo de produção e, deve ser avaliada, uma vez que a associação de patógenos às sementes pode implicar em redução do rendimento e comprometimento da qualidade das mesmas (Machado, 1988).

Dentre os fatores que afetam a qualidade das sementes, está a época da colheita, sendo que, geralmente, aquelas colhidas antes ou após a maturidade fisiológica podem apresentar menor potencial de germinação e vigor (Carvalho e Nakagawa, 2000). A partir da maturidade fisiológica, tende a ocorrer redução da qualidade das sementes, cuja velocidade de deterioração é influenciada pelos fatores ambientais, especialmente aquelas predominantes na fase final de maturação (Popinigis, 1985).

Portanto, tendo em vista a possibilidade de colheita de inflorescências de zínia com idades e tamanhos diferenciados, devido ao seu longo período de florescimento, o objetivo do trabalho foi avaliar a influência de diferentes épocas de colheita na qualidade fisiológica e sanitária de sementes de zínia.

\section{MATERIAL E MÉTODOS}

O trabalho foi conduzido no laboratório de Fitopatologia do Departamento de Defesa Fitossanitária da Universidade Federal de Santa Maria (UFSM), RS. As sementes zínia foram originadas de plantas semeadas em outubro de 2004, na área experimental do Departamento de Fitotecnia (UFSM). Os capítulos foram coletados manualmente e de acordo com a sua aparência, em sete épocas: 17 de janeiro, 10 de fevereiro, 15 de março (coleta A), 23 de março (coleta B), 12 de abril, 10 de maio (coleta A) e 29 de maio (coleta B) do ano de 2005. Aqueles provenientes de coletas em janeiro, fevereiro e maio (A) apresentavam-se verdolengos, os demais tinham aparência seca.

Para a avaliação da qualidade fisiológica, as sementes foram submetidas aos seguintes testes: grau de umidade realizado em estufa a $105 \pm 3{ }^{\circ} \mathrm{C}$ por 24 horas, utilizandose quatro subamostras com $5 \mathrm{~g}$ para cada época de colheita (Brasil, 1992); germinação - conduzida com 200 sementes, oito repetições de 25 sementes, distribuídas sobre duas folhas de papel filtro umedecidas com água destilada na proporção de 2,5 vezes o peso do papel, em caixas plásticas do tipo gerbox. As caixas permaneceram em germinador a $25^{\circ} \mathrm{C}$ com fotoperíodo de 12 horas e as avaliações foram realizadas aos cinco e dez dias após a semeadura (Brasil, 
1992). Os resultados foram expressos em porcentagem de plântulas normais, avaliando-se também a porcentagem de sementes mortas; primeira contagem de germinação - realizada conjuntamente com o teste de germinação. Constituiu-se no registro das porcentagens de plântulas normais obtidas na primeira contagem da germinação (quinto dia); comprimento de plântulas - avaliou-se o comprimento médio das plântulas normais obtidas aos dez dias no teste de germinação, com o auxílio de régua milimetrada. O comprimento médio foi obtido somando-se as medidas de cada repetição e dividindo-se pelo número de plântulas normais mensuradas, com resultados expressos em centímetros/plântula, conforme descrito por Nakagawa (1999); massa fresca de plântulas - obtido pela pesagem, em balança com precisão de $0,01 \mathrm{~g}$, das plântulas normais obtidas aos dez dias no teste de germinação. Calculouse o peso médio somando-se o peso de cada repetição e dividindo-se pelo número de plântulas normais pesadas, com resultados expressos em g/plântulas; classificação do vigor de plântulas - foi conduzido conjuntamente com o teste de germinação, consistindo no registro da porcentagem de plântulas normais "fortes" verificadas na primeira contagem de germinação, sendo consideradas normais "fortes" aquelas que se apresentavam sadias, com cotilédones e sistema radicular bem desenvolvido, conforme Nakagawa, 1999; emergência de plântulas em campo - conduzido em casa de vegetação, utilizando-se bandejas contendo substrato comercial, realizada com quatro repetições de dez sementes para cada época de colheita. Foram feitas irrigações sempre que necessário e a avaliação foi realizada aos trinta dias após a semeadura, computando-se a porcentagem de plântulas emergidas; comprimento de planta - realizado em conjunto com o teste de emergência em campo, avaliando-se o comprimento médio das plantas obtidas aos trinta dias após a semeadura, determinados em centímetros, com o auxílio de uma régua milimetrada. Calculou-se o comprimento médio por planta $(\mathrm{cm} /$ planta), dividindo o somatório dos valores obtidos pelo número de plantas mensuradas.

$\mathrm{Na}$ avaliação da qualidade sanitária, foram utilizadas 200 sementes, as quais foram colocadas em caixas "gerbox" contendo duas folhas de papel filtro umedecidas com água destilada na proporção de 2,5 vezes o peso do papel. A germinação das sementes foi inibida pelo método do congelamento por 24 horas. Em seguida, foram incubadas a $25^{\circ} \mathrm{C}$ por sete dias, com 12 horas de regime de luz. Após este período, as sementes foram analisadas com o auxílio de lupa estereoscópica e microscópio óptico para observação das estruturas morfológicas dos fungos, os quais foram identificados ao nível de gênero, com o auxílio da bibliografia especializada de Barnett e Hunter (1998), determinando-se a porcentagem de sementes infestadas por fungos.

Para a análise estatística o delineamento experimental empregado foi o completamente casualizado. Os dados obtidos em cada teste foram submetidos à análise de variância e regressão em nível de $5 \%$, pelo teste $\mathrm{F}$, empregandose o Programa de Análise Estatística SANEST ${ }^{\circledR}$ (Zonta e Machado, 1987).

\section{RESULTADOS E DISCUSSÃO}

$\mathrm{Na}$ Tabela 1 encontram-se os dados meteorológicos referentes aos meses de colheita das sementes de zínia, os quais foram coletados na estação meteorológica da UFSM. Esses, assim como os dados referentes ao grau de umidade das sementes por ocasião da colheita (Figura 1), não foram analisados estatisticamente, servindo como comparativos na avaliação da qualidade das mesmas.

TABELA1. Médias de temperatura $\left({ }^{\circ} \mathrm{C}\right)$, umidade relativa (\%) e precipitação pluviométrica $(\mathrm{mm})$ registradas durante os meses de colheita das sementes de Zinnia elegans Jacq. em 2005. Santa Maria-RS, 2006.

\begin{tabular}{cccc}
\hline $\begin{array}{c}\text { Meses de } \\
\text { colheita }\end{array}$ & $\begin{array}{c}\text { Temperatura } \\
\left({ }^{\circ} \mathrm{C}\right)\end{array}$ & $\begin{array}{c}\text { Umidade } \\
\text { Relativa }(\%)\end{array}$ & $\begin{array}{c}\text { Precipitação } \\
(\mathrm{mm})\end{array}$ \\
\hline Janeiro & 25,9 & 64 & 49,1 \\
Fevereiro & 24,3 & 71 & 59,4 \\
Março & 23,7 & 68 & 55,4 \\
Abril & 19,1 & 84 & 276,1 \\
Maio & 17,8 & 83 & 183,7 \\
\hline
\end{tabular}

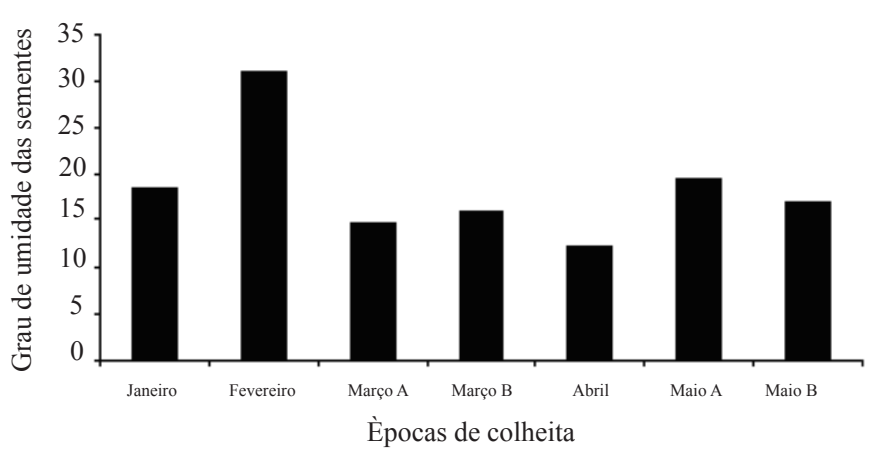

FIGURA 1. Grau de umidade (\%) das sementes de Zinnia elegans Jacq. colhidas em diferentes épocas: janeiro (1), fevereiro (2), março $A$ (3), março B (4), abril (5), maio A (6) e maio B (7) de 2005. Santa Maria, 2006. 
Observou-se variação no grau de umidade das sementes de zínia em relação às diferentes épocas de colheita. Sementes provenientes da colheita realizada em fevereiro apresentaram a maior porcentagem de umidade (30,94\%) em relação às demais, janeiro (18,92\%), março $\mathrm{A}(14,82 \%)$, março B (15,83\%), abril (12,08\%); maio A (19,52\%) e maio B (17,02\%). Essa diferença provavelmente se deve ao fato
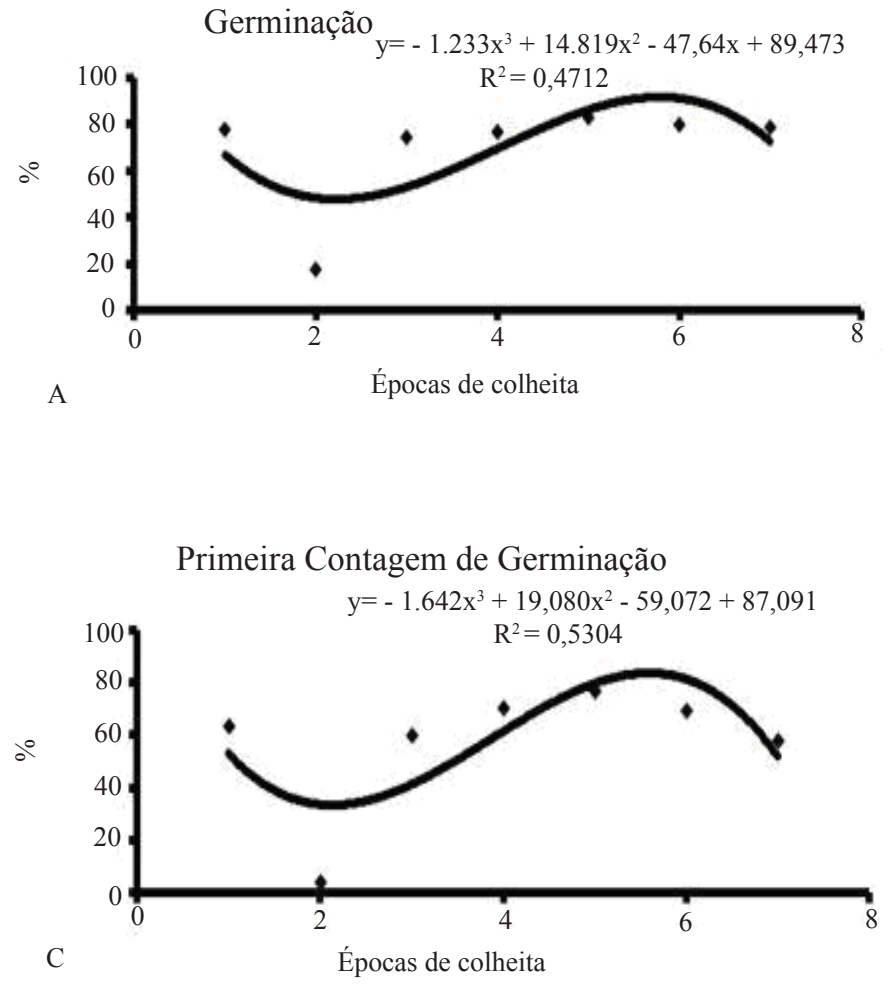

Massa Fresca de Plântulas

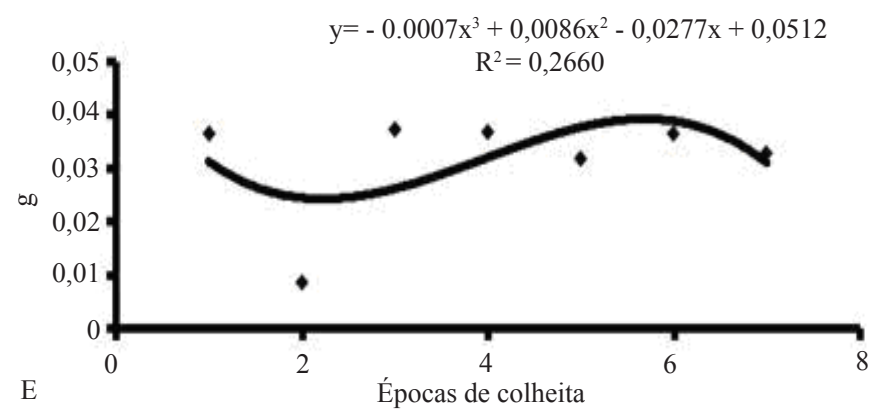

de que as sementes, verdes e ainda imaturas, apresentam naturalmente maior quantidade de água em seus tecidos.

Na Figura 2, verifica-se o comportamento polinomial dos valores médios percentuais de germinação, sementes mortas, primeira contagem de germinação, plântulas normais fortes, massa fresca de plântulas e comprimento de plântulas, ajustados ao modelo cúbico.

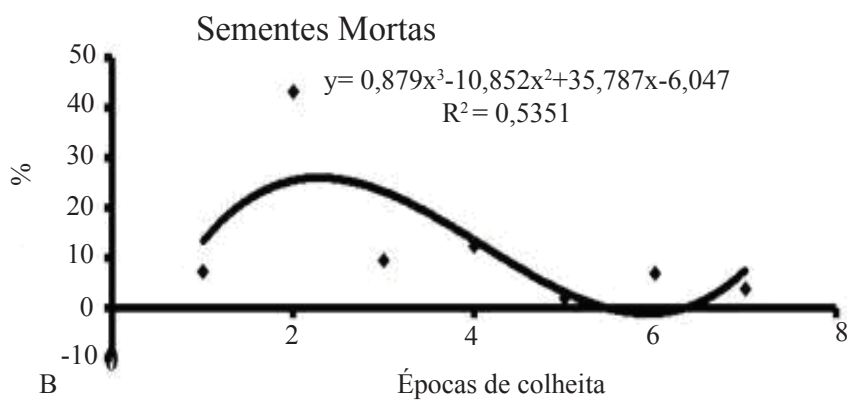

Plântulas Normais Fortes

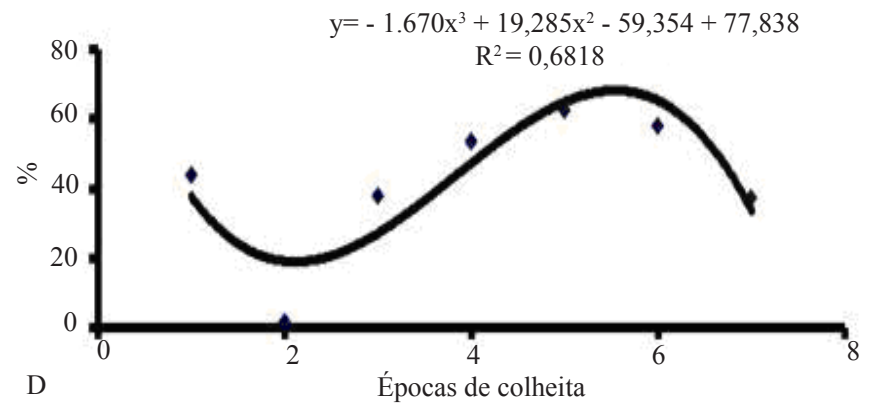

Comprimento de Plântulas

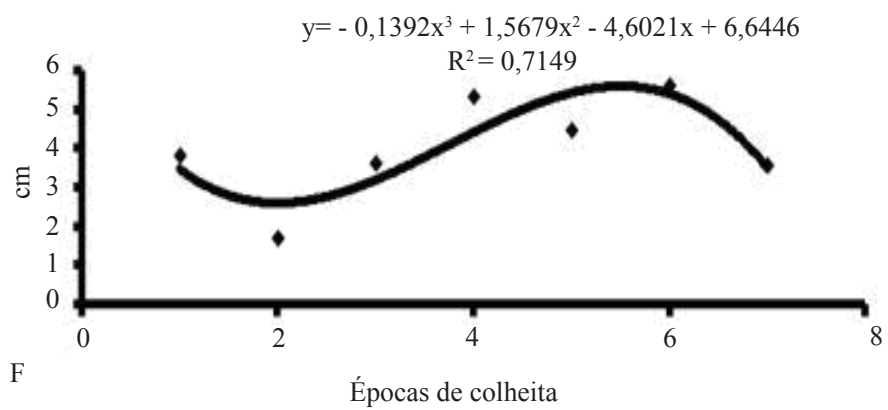

FIGURA 2. Valores médios de germinação (A), sementes mortas (B), primeira contagem de germinação (C), plântulas normais fortes (D), massa fresca de plântulas (E) e comprimento de plântulas (F) de Zinnia elegans Jacq. colhidas em diferentes épocas: janeiro (1), fevereiro (2), março A (3), março B (4), abril (5), maio A (6) e maio B (7) de 2005. Santa Maria, 2006. 
A germinação (Figura 2 - A) foi semelhante em todas as épocas de colheitas, com exceção das sementes colhidas no mês de fevereiro, as quais obtiveram a menor porcentagem de germinação (17\%). Esse resultado, provavelmente, se deve a combinação do alto grau de umidade das sementes e da imaturidade das mesmas, o que afetou sua qualidade fisiológica. Uma colheita precoce, isto é, quando as sementes não estão desenvolvidas por completo e apresentam um alto conteúdo de umidade, leva a um decréscimo na germinação e consequentemente na produção (Smiderle et al, 2008).

Essa combinação de fatores, grau de umidade acentuado e colheita antecipada, pode ter sido o motivo pelo qual houve eleva proporção de sementes mortas quando a colheita foi realizada em fevereiro (Figura $2-\mathrm{B}$ ). De acordo com Carvalho e Nakagawa (2000), o grau de umidade elevado prejudica a viabilidade da semente, pois favorece a elevação da sua temperatura devido a processos respiratórios e de uma maior atividade de microrganismos, o que, conseqüentemente, leva a morte das mesmas, como pode ser verificado nesse trabalho.

Os resultados obtidos na avaliação do vigor das sementes pelos testes de primeira contagem de germinação, classificação do vigor de plântulas, massa fresca de plântulas e comprimento de plântula (Figura 2- C, D, E e F) acompanharam a mesma tendência do teste de germinação. Estes resultados permitem ratificar que o teor

Germinação

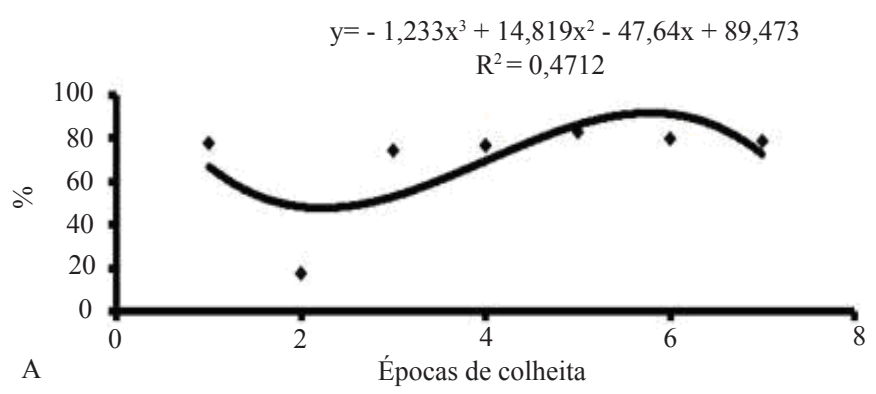

de água das sementes é de extrema importância para sua qualidade, principalmente naquelas espécies que apresentam desuniformidade na maturação, como Z. elegans.

Embora as condições climáticas da região de produção possam influenciar na qualidade das sementes, o conjunto de dados obtidos na avaliação fisiológica das sementes de zínia, demonstrou que grau de umidade das sementes foi fator determinante no presente trabalho. Conforme se observou, sementes resultantes da colheita de abril apresentaram-se mais vigorosas, com maior porcentagem de germinação $(83 \%)$ e menor porcentagem de sementes mortas $(1 \%)$, fato que provavelmente pode ser explicado pelo seu menor teor de água (12,08\%).

Pela Figura 3 as equações de regressão obtidas para os testes de comprimento de planta e emergência em campo. Observa-se que não houve uma diferença acentuada nesses testes entre as épocas de colheita; no entanto, pode-se verificar que sementes colhidas em março (A) demonstraram maior porcentagem de emergência e comprimento de plântulas nas condições de campo. A discordância desses resultados obtidos em campo com os verificados em laboratório implica na necessidade de realização do maior número possível de testes antes de classificar as sementes colhidas em diferentes épocas em relação ao potencial fisiológico, pois cada teste fornece informações complementares para a decisão a respeito da classificação quanto à qualidade das sementes.

Sementes Mortas

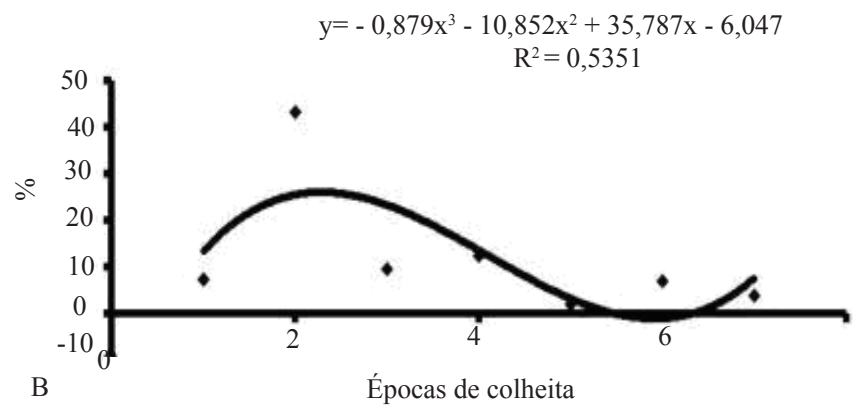

FIGURA 3. Emergência de plântulas em campo (A) e comprimento de plantas (B) de Zinnia elegans Jacq. colhidas em diferentes épocas: janeiro (1), fevereiro (2), março A (3), março B (4), abril (5), maio A (6) e maio B (7) de 2005. Santa Maria, 2006.

Todavia, tanto os resultados obtidos nos testes que avaliaram a qualidade fisiológica das sementes em laboratório como em campo permitiram inferir que sementes colhidas com menor grau de umidade apresentaram maior vigor em relação às demais, pois se observa que os melhores resultados foram obtidos com sementes colhidas em abril e março (A), as quais apresentaram os menores teores de água 12, $08 \% \mathrm{e}$ $14,82 \%$, respectivamente.

$\mathrm{Na}$ avaliação da qualidade sanitária foram detectados os seguintes fungos associados às sementes de zínia: Alternaria 
spp., Curvularia spp., Epicocum spp. e Fusarium spp., Aspergillus spp., Penicilium spp. e Drechslera spp. (Figura 4). Segundo Silva-Mann et al. (2002), o aspecto de sanidade de sementes, do ponto de vista de diagnóstico e controle de

Incidência de Alternaria spp.

A

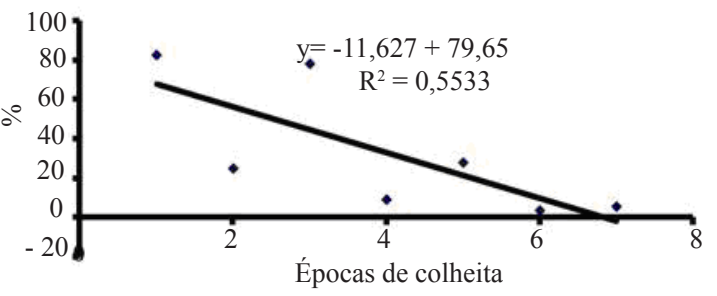

Incidência de Epicocum spp.

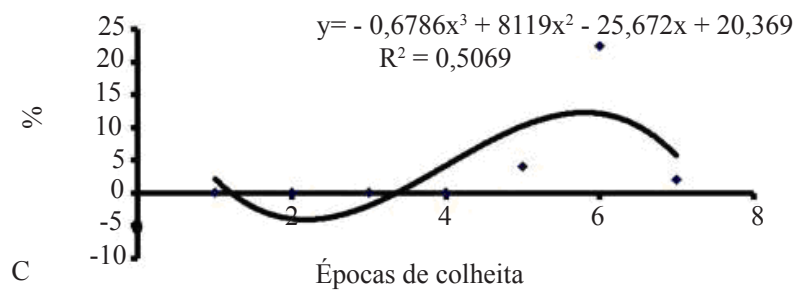

Incidência de Aspergillus spp.

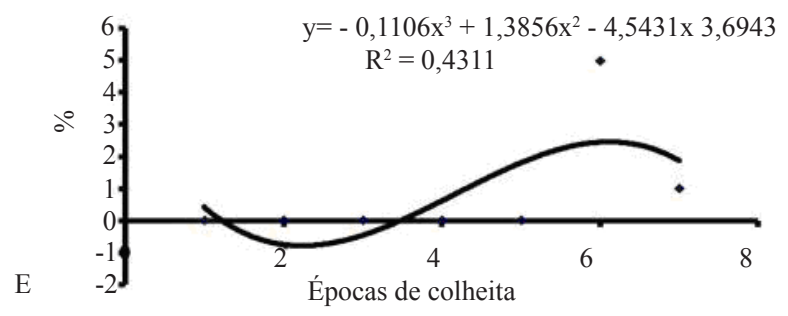

doenças em plantas, tem assumido uma posição de destaque mundial, devido ao acentuado número de patógenos que podem ser transmitidos pelas sementes.

ncidência de Curvularia spp.

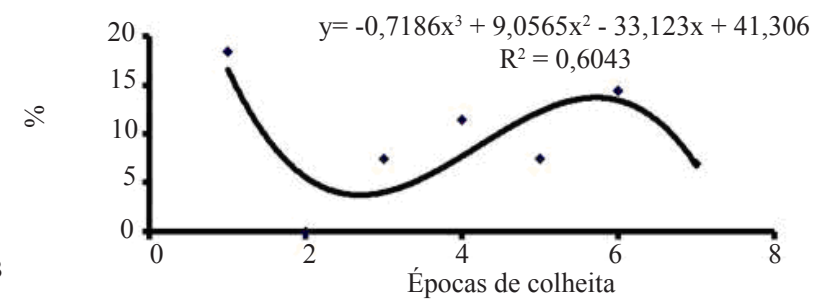

Incidência de Fusarium spp.

D

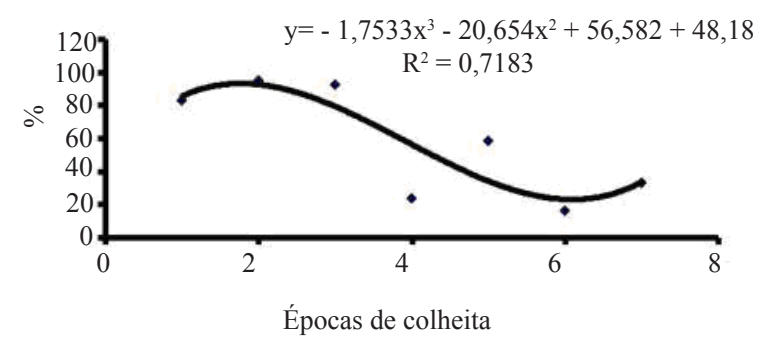

Incidência de Penicillium spp.

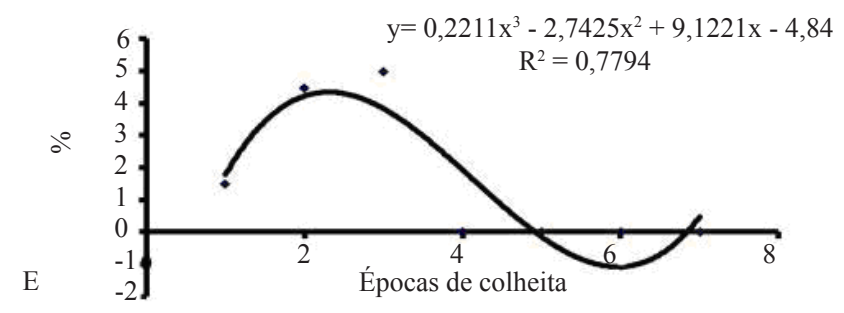

Incidência de Drechslera spp.

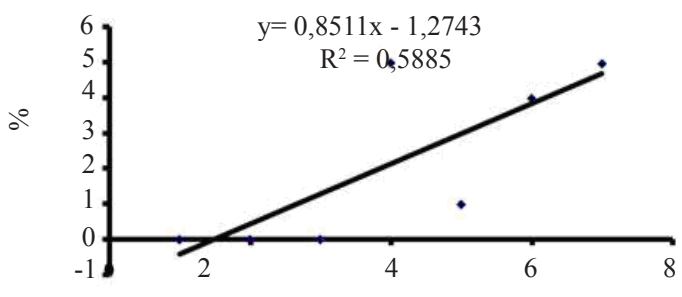

H

Épocas de colheita

FIGURA 4. Porcentagem de incidência de Alternaria spp., Curvularia spp., Epicocum spp., Fusarium spp., Aspergillus spp., Penicillium spp. e Drechslera em sementes de Zinnia elegans Jacq. colhidas em diferentes épocas: janeiro (1), fevereiro (2), março A (3), março B (4), abril (5), maio A (6) e maio B (7) de 2005, Santa Maria, 2006. 
Alternaria spp. e Fusarium spp. ocorreram nas sementes em todas as épocas de colheita, sendo que a incidência mais acentuada foi de Fusarium spp. com (95\%) naquelas colhidas no mês de fevereiro. Este patógeno, em associação com plantas ornamentais, é citado na literatura causando podridões de caule e raiz (Chase, 1992), sendo, portanto, considerado um fungo patogênico de importância relevante no setor de produção de plantas e flores ornamentais.

Alternaria spp. juntamente com Curvularia spp. apresentaram maiores porcentagens de incidência, 18\% e 83\% respectivamente, em sementes colhidas no mês de janeiro. Observa-se que as condições climáticas para essa época de colheita foram de alta temperatura, baixa precipitação pluviométrica e baixa umidade relativa. No entanto, essas podem ser as condições necessárias para o desenvolvimento desses fungos em capítulos de zínia, permitindo assim que eles se encontrassem mais expressivamente nas sementes. Tanto Alternaria spp. quanto Curvularia spp. são citados na literatura comocausadores de doenças em plantas ornamentais. Em levantamento de doenças fúngicas de plantas ornamentais realizados por Sologuren e Juliatti (2007), Alternaria foi o gênero de maior ocorrência nas espécies estudadas. Furtado et al. (2007) demonstraram que duas espécies de Curvularia, C. lunata e C. eragrostidis, como agentes causais de podridões generalizadas nas inflorescências de Tapeinochilus ananassae, planta ornamental tropical, ocasionando perdas severas na produção.

Por outro lado, sementes colhidas em maio (A) foram as que apresentaram maior incidência de Epicocum spp. (22\%) e Aspergillus spp. (5\%). Já o fungo Drechslera spp. (5\%) ocorreu em maior porcentagem em sementes de março (B) e, Penicillium spp. (5\%) em março (A). Tanaka e Corrêa (1981) afirmam que Aspergillus spp. e Penicillium spp. contribuem para a redução do poder germinativo de sementes de várias espécies vegetais, dados que não condizem com esse trabalho, possivelmente, devido a baixa incidência encontrada, $5 \%$ para ambos.

A diferença observada na porcentagem de incidência de cada um dos patógenos nas diferentes épocas de colheita deve-se a particularidade do patossistema, pois cada patógeno possui características próprias para que ocorra seu desenvolvimento e sua transmissão. Foi observado por Leukel (1933) que a transmissão de Dreschslera graminea em cevada é favorecida por temperaturas abaixo de $15^{\circ} \mathrm{C}$ e diminui drasticamente em temperaturas superiores a $20^{\circ} \mathrm{C}$. Em cenoura, segundo Dhingra (2005), a taxa de transmissão de Alternaria dauci é alta à temperatura de $25^{\circ} \mathrm{C}$, já Raut (1983) constatou que Macrophomina phaseolina em sementes de girassol teve desenvolvimento expressivo à temperatura de $35^{\circ} \mathrm{C}$.

Portanto, colher na época certa, ou seja, quando as sementes de zínia apresentam-se aparentemente secas é de fundamental importância para se obter sementes de melhor qualidade fisiológica e sanitária.

\section{CONCLUSÕES}

A época de colheita dos capítulos, de acordo com sua aparência, influencia na qualidade fisiológica e sanitária de sementes e Zinnia elegans Jacq.

Sementes colhidas em estádio seco, com grau de umidade abaixo de $14,8 \%$, apresentam maior qualidade fisiológica.

A ocorrência de patógenos varia conforme a época de colheita, sendo que sementes provenientes da colheita de fevereiro apresentam maior porcentagem de incidência Fusarium spp.

\section{REFERÊNCIAS}

BARNETT, H. L.; HUNTER, B. B. Illustrated genera of imperfect fungi. St Paul, Minnesota: APS Press, 1998. $218 \mathrm{p}$.

BRASIL. Ministério da Agricultura e Reforma Agrária. Regras para análise de sementes. Brasília: SNDA/DNDV/ CLAV, 1992. 365p.

CARVALHO, N. M.; NAKAGAWA, J. Sementes: ciência, tecnologia e produção. 4. ed. Jaboticabal: FUNEP, 2000. $588 \mathrm{p}$.

CHASE, A. R. Compendium of ornamental foliage plant diseases. St. Paul, Minnesota: APS Press, 1992. 92p.

DHINGRA, O. D. Teoria da Transmissão de Patógenos Fúngicos por Sementes in ZAMBOLIN, L. (Ed.). Sementes: Qualidade Fitossanitária. Viçosa: UFV. 2005. 11-75p.

FURTADO, D. C. de M.; AMORIN, E. P. da R.; GALVÃO A. L. B. GARNAÚBA, J. P.; OLIVEIRA, M. N. de. Ocorrência de Curvularia lunata e Curvularia eragrostidis em Tapeinichilus ananassae no estado de Alagoas. Summa Phytopathologica, Botucatu, v.33, n.2, p.201-201, 2007.

GUIMARÃES, T.G.; OLIVEIRA, D.A.; MANTOVANIALVARENGA, E.; GROSSI, J.A.S. Maturação fisiológica de sementes de zínia (Zinnia elegans Jacq.). Revista Brasileira de Sementes, Brasília, v.20, n.1, p. 7-11, 1998.

JUNQUEIRA, A.H.; PEETZ, MS. Os pólos de produção de flores e plantas ornamentais do Brasil: uma análise do potencial exportador. Revista Brasileira de Horticultura 
Ornamental, Campinas, v.8, n.1/12, p. 25-47, 2002.

LEUKEL, R. W. Effect of certain environmental factors on strip disease of barley and the control of the disease by seed treatment. U. S. Department Agriculture Tech. Bull., New York, v.341, p.39, 1933.

LORENZI, H.; SOUZA, H.M. Plantas ornamentais no Brasil: arbustivas, herbáceas e trepadeiras, 2ed. São Paulo. Instituto Plantarum de Estudos da Flora. 1999. 1088 p.

MACHADO, J.C. Patologia de sementes: fundamentos e aplicações. Lavras: ESAL/FAEPE, 1988. 107p.

NAKAGAWA, J. Teste de vigor baseado na avaliação das plântulas. In: KRZYZANOWSKY, F.C.; VIEIRA, R.D.; FRANÇA NETO, J.B. (Ed.) Vigor de sementes: conceitos e testes. Londrina: ABRATES, 1999. p.2-1 -2-21.

POPINIGIS, F. Fisiologia da semente. Brasília: AGIPLAN, 1985. $289 \mathrm{p}$.

RAUT, J. G. Transmission of seed-borne Macrophomina phaseolina in sunflower. Seed Science \& Technology, Zurich, v.11, p.807-814, 1983.

SILVA-MANN, R.; SALGADO, K. C. C.; VIEIRA, M. G.
G. C.; MACHADO, J. C. Variabilidade genética de isolados do complexo Colletotrichum associados a sementes de algodoeiro, por meio de técnicas moleculares e inoculação em plantas. Fitopatologia Brasileira, Brasília, v.27, n.1, p. 27-32, 2002.

SMIDERLE, O. J.; PEREIRA, P. R. V. da S. Épocas de colheita e qualidade fisiológica das sementes de arroz irrigado cultivar BRS 7 TAIM, em Roraima. Revista Brasileira de Sementes, Brasília, v.30, n.1, p.74-80, 2008.

SOlOGURE, F. J.; JULIATTI, F. C. Doenças fúngicas em plantas ornamentais em Uberlândia - MG. Bioscience Journal, Uberlândia, v.33, n.2, p.42 - 52, 2007.

TANAKA, M.A.S.; CORRÊA, M.U. Influência de Aspergillus e Penicillium no armazenamento de sementes de feijão (Phaseolus vulgaris L.) Fitopatologia Brasileira, Brasília, v.6, n.3, p. 451-456, 1981.

TORRES, A.M. Taxonomy of Zinnia. Brittonia, New York. v.15, 1963. p. 1-25.

ZONTA, E.P.; MACHADO, A.A. Sistema de análise estatística para microcomputadores - SANEST. Pelotas: UFPel, 1987. 